\author{
Military Technical College \\ Kobry El-Kobbah, \\ Cairo, Egypt.
}

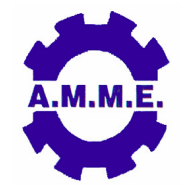

\title{
ON LOSS MECHANISM THROUGH REACTION TURBINE CASCADE: EFFECT OF SPACE-CHORD RATIO
}

\author{
M. Govardhan* and V. V. Anandrao*
}

\begin{abstract}
Investigations on reaction turbine cascade were conducted with the aim of ascertaining the influence of space-chord ratio on secondary flows and losses. The turbine cascade had high deflection reaction blades with a geometric deflection of $82^{\circ}$. Structured hexahedral elements were used for meshing. Periodic boundary condition for periodic faces and no slip boundary condition for endwall, blade surfaces were applied. Experimental inlet profile was specified and the SST K- $\omega$ turbulence with transition was used for closure. Five space-chord ratios; namely, $\mathrm{S} / \mathrm{Ch}=0.42,0.60,0.70,0.84$ and 1.04 were varied at constant stagger and incidence angles. Space-chord ratio alters blade loading influencing secondary flows characteristics. As space-chord ratio is increased, secondary loss coefficient increases primarily due to the increased blade loading resulting in increased cross channel deflection. Space-chord ratio influences loss levels. There exists an optimum space-chord ratio at which total pressure losses are minimum.
\end{abstract}

\section{KEYWORDS}

space-chord ratio, secondary losses, static presure coefficient, passage vortex, flow angle, deviation.

\footnotetext{
* Professor, Dept. of Mech. Eng., I.I.T. Madras, Chennai, India

** Graduate Student, Dept. of Mech. Eng., I.I.T. Madras, Chennai, India
} 


\section{NOMENCLATURE}
AR
Aspect ratio $=(\mathrm{h} / \mathrm{ch})$
b
Axial chord (mm)
C
Velocity $(\mathrm{m} / \mathrm{s})$
Ch
Chord (mm)
$\mathrm{C}_{\mathrm{p}}$
Surface static pressure coefficient $=\left(\frac{\overline{\bar{P}}_{\mathrm{s}}-\mathrm{P}_{\mathrm{s} 1}}{\frac{1}{2} \rho \overline{\overline{\mathrm{C}}}_{2}{ }^{2}}\right)$
$\mathrm{h}$
Blade span ( $\mathrm{mm})$
$P$
Pressure $(\mathrm{Pa})$
$\mathrm{Re}$
Reynolds number
S
Spacing $(\mathrm{mm})$
$\mathrm{x}$
Distance in axial direction ( $\mathrm{mm}$ )
$\mathrm{y}$
Distance in pitchwise direction $(\mathrm{mm})$
z
Distance in spanwise direction ( $\mathrm{mm}$ )
Z
Non dimensional span (z/h)

\section{Greek Letters}

$\alpha$

Flow angle (deg.)

$\beta$

Blade angle (deg.)

$\delta$

Boundary layer thickness (mm)

$\gamma$

Stagger angle (deg.)

$\psi_{\text {loss }}$

Total pressure loss coefficient $=\left(\frac{\overline{\bar{P}}_{\mathrm{o} 1}-\mathrm{P}_{\mathrm{o}}}{\frac{1}{2} \rho \overline{\overline{\mathrm{C}}}_{2}^{2}}\right)$

\section{Subscripts}

1

2

0

S

\section{Superscripts}

Pitch wise mass averaged value

$=$
Inlet

Exit

Total

Static 


\section{INTRODUCTION}

The nature of flow in Turbomachinery is three-dimensional mainly due to the combined effects of blade and endwall boundary layers, flow separation, formation of horseshoe vortex near the blade leading edge, tip leakage flow and other secondary flows, (Langston [1], Aunapu et al. [2], Dossena et al.[3], Sharma and Butler [4], Wang et al. [5], Moore and Adhye [6], Krishna Nanda Kumar and Govardhan [7]). Perdichizzi and Dossena (8) performed experiments to study the effect of incidence angle and space-chord ratio on secondary flows in a turbine cascade. They concluded that as the incidence angle and space-chord ratio are increased, the region covered by the secondary flows extends progressively towards the midspan. High levels of streamwise vortices and intense cross flow at the end wall took place at large incidence angles and low solidities. Xu et al. (9) did computational analysis of space-chord ratio effects on the secondary flows in a turbine passage. They observed that space-chord ratio has a strong influence in generating secondary flows and losses. For small blade spacing, the pressure side leg of the horse-shoe vortex merged and dissipated very fast and suction side passage core developed slowly which caused a small total pressure loss. Dossena et al. (3) performed experiments to study influence of incidence angle, space-chord ratio, Mach number and stagger angle on linear turbine cascade. They observed that secondary flow and kinetic energy loss distribution are mainly influenced by the incidence angle and space-chord ratio. Incidence angle causes changes in loss contours shape and in location and magnitude of secondary flows; furthermore, incidence angle increase causes quite linear increase in loss level. Space -chord ratio influences particularly the loss level and secondary flows and has non-linear effect on overall loss.

Though secondary flows and losses depend on several parameters, studies on the effect of space-chord ratio are limited. Hence the present investigations are focused on high aspect ratio reaction turbine blades with a particular attention to the effect of space-chord ratio on secondary loss. Effect of entry boundary layer which imparts three-dimensional flow through turbine blades is ignored in many studies, which is vital and is considered in the present study.

\section{COMPUTATIONAL MODEL AND NUMERICAL SIMULATIONM}

\section{Governing Equations}

The governing equations are integrated over each control volume, such that the relevant quantity (mass, momentum, energy etc.) is conserved in a discrete sense for each control volume.

\section{Continuity equation}

$$
\frac{\partial \rho}{\partial t}+\nabla \bullet(\rho C)=0
$$

where $C=u \hat{i}+v \hat{j}+w \hat{k}$ 
As the flow is assumed steady, $\frac{\partial \rho}{\partial t}=0$ and continuity equation then reduces to

$\nabla \bullet(\rho \boldsymbol{C})=0$

\section{Momentum equation}

$\frac{\partial \rho \boldsymbol{C}}{\partial t}+\nabla \bullet(\rho \boldsymbol{C} \otimes \boldsymbol{C})=\nabla \bullet\left(-\rho \delta+\mu\left(\nabla \boldsymbol{C}+(\nabla \boldsymbol{C})^{T}\right)\right)+S_{M}$

$S_{M}$ refers to momentum sources.

As the flow is assumed to be in steady state, $\frac{\partial \rho \boldsymbol{C}}{\partial t}=0$

Momentum equation then reduces to

$\nabla \bullet(\rho \boldsymbol{C} \otimes \boldsymbol{C})=\nabla \bullet\left(-\rho \delta+\mu\left(\nabla \boldsymbol{C}+(\nabla \boldsymbol{C})^{T}\right)\right)+S_{M}$

\section{Energy equation}

$\frac{\partial \rho h_{o}}{\partial t}-\frac{\partial p}{\partial t}+\nabla \bullet\left(\rho C h_{o}\right)=\nabla \bullet(\lambda \nabla T)+S_{E}$

For a steady flow, $\frac{\partial \rho h_{o}}{\partial t}=0, \quad \frac{\partial p}{\partial t}=0$

Energy equation in this case will be reduced to

$\nabla \bullet\left(\rho C h_{o}\right)=\nabla \bullet(\lambda \nabla T)+S_{E}$

where $h=h(p, T)$ and $\mathrm{h}_{\mathrm{o}}=$ specific total enthalpy

$h_{o}=h+\frac{1}{2} C^{2}$

If viscous work is significant, an additional term is used in the RHS of the energy equation to account for the effect of viscous shear. The energy equation then becomes,

$\frac{\partial \rho h_{o}}{\partial t}-\frac{\partial p}{\partial t}+\nabla \bullet\left(\rho \boldsymbol{C} h_{o}\right)=\nabla \bullet(\lambda \nabla T)+\left[\nabla \bullet\left\{\mu\left[\nabla \boldsymbol{C}+(\nabla \boldsymbol{C})^{T}-\frac{2}{3} \nabla \bullet \boldsymbol{C} \boldsymbol{\delta}\right] \boldsymbol{C}\right\}+S_{E}\right]$

The additional term represents the work due to external momentum sources.

A total of seven unknowns are involved, $(u, v, w, p, T, h, \rho)$ in five equations but the set can be closed by adding two algebraic thermodynamic equations, namely; equation of state relating density, $\rho$ to temperature, $T$ and pressure, $p$ and constitutive equation relating enthalpy, $h$ to temperature, $T$ and pressure, $p$. 


\section{Equation of state for $\rho$}

For an ideal gases, the relationship described by ideal gas law,

$\rho=\frac{w\left(p+p_{\text {ref }}\right)}{R_{0} T}$

where $w$ is the molecular weight of the gas, and $R_{0}$ is the universal gas constant.

\section{Equation of state for enthalpy (constitutive equation)}

The algebraic thermodynamic relation for enthalpy is:

$$
h_{2}-h_{1}=\int_{T_{1}}^{T_{2}} C_{p} d t+\int_{p_{1}}^{p_{2}} \frac{1}{\rho}\left[1+\frac{T}{\rho}\left(\frac{\partial \rho}{\partial T}\right)_{p}\right] d p
$$

In the above equation, the first part is equivalent to the change in enthalpy for an ideal gas and the second step is a correction required for the real fluid. If both density and specific heat are constants, the above equation then reduces to

$$
d h=C_{p} d T+\frac{d p}{\rho}
$$

Geometry which is required for the CFD simulation is built in AutoCAD 2006. The blades are of reaction type with an inlet angle of $22^{\circ}$ and an outlet angle of $-60^{\circ}$. The blade chord and the blade height are $102 \mathrm{~mm}$ and $400 \mathrm{~mm}$ respectively. Figure 1 shows the view of the cascade with details of the blade. Table 1 gives pertinent details of the cascade. As the aspect ratio is 3.9, the flow is two-dimensional at the mid span. Hence, the mid span losses are taken as profile losses. Total of five geometries were created for five S/Ch values; namely, $\mathrm{S} / \mathrm{Ch}=0.42,0.60,0.70,0.84$ and 1.04, (Fig.2). For all S/Ch ratios, stager angle was kept constant and the incidence angle was maintained at zero degrees. Upstream and downstream length of the fluid domain is created to have 1.0 and 0.7 times of the axial chord respectively. The fluid domain is than exported as ACIS format to GAMBIT2.3 for grid generation. While creating the grid, a dense grid is created in the regions where velocity gradients are expected to be high. A fine grid near the walls is provided to capture boundary layer effects. A still finer grid close to the leading and trailing edges of the blade is provided to capture the entrance effects in-front of the leading edge and wakes behind the trailing edge of the blade, (Fig.3). The element thickness near the endwall regions is built to achieve $y+\approx 1$ value for solving $k-\omega$ SST with an option of transitional flows. The quality of the grid plays an important role in the accuracy and stability of the numerical computation. The skewness in the mesh was limited to 0.7 . Grid independence study was conducted and finally mesh with 0.83 million cells was selected. At inlet velocity profile was prescribed based on the measured experimental values. Wall boundary conditions are used to bound fluid and solid regions. No-slip condition was applied on the blade and endwall surfaces. Since the process is assumed adiabatic, the heat flux through the wall is set to zero. As the fluid domain is symmetric about midspan, symmetry is utilized to reduce the 
computational domain. With inlet velocity as boundary condition, mass flow rate is automatically passed proportional to the blade spacing.

\section{RESULTS AND DISCUSSIONS}

From the experimentally available inlet velocity profile a power law curve $U=U_{\text {free }}\left(\frac{z}{\delta}\right)^{1 / 9}$ was fitted, where $\delta=42.3 \mathrm{~mm}$ (experimental). At inlet boundary condition, velocity profile was given with the help UDF (User Defined function). The numerical results for a space-chord ratio of 0.7 was compared with experimental results of Govardhan and Pramod Kumar Maharia [10]. Computational results of flow angle, velocity, tangential and axial velocities are in excellent agreement with experimental results, (Figs.4 and 5).

\section{Surface Static Pressure Coefficient $\left(\mathbf{C}_{\mathrm{p}}\right)$}

Figure 6 shows static pressure coefficients at the endwall for $\mathrm{S} / \mathrm{Ch}=0.42,0.7,0.84$ and 1.04 respectively. Static pressure coefficient is defined as the ratio of difference in static pressures obtained between the measured location and atmospheric pressure to the mass averaged dynamic head measured at the cascade exit. Due to the large blade curvature, the pressure gradient across pressure and suction surfaces is large. As space-chord ratio is increased $C_{p}$ on pressure side is increasing, with consequent increase in blade loading. $C_{p}$ on suction side is decreasing with increase in $\mathrm{S} / \mathrm{Ch}$ except for a very low $\mathrm{S} / \mathrm{Ch}=0.42$. Due to the strong secondary flow effect, the minimum pressure occurs in the passage away from the blade surface. A clear low-pressure zone exists on the suction side of the blade for all $\mathrm{S} / \mathrm{Ch}$ ratios.

Stagnation region near the leading edge shifts towards pressure surface as $\mathrm{S} / \mathrm{Ch}$ is increased. For S/Ch 1.04, a large region encompassing leading edge and pressure surface is observed. The low pressure region on suction surface increases with $\mathrm{S} / \mathrm{Ch}$ and the region spreads in both chord-wise and pitchwise directions. The pressure coefficient is lower for large S/Ch. The blade loading i.e. the difference between the pressure and suction surface is seen to increase with $\mathrm{S} / \mathrm{Ch}$. This is because as $\mathrm{S} / \mathrm{Ch}$ increases the flow constraint from the blade becomes small and therefore, the blade's local curvature plays an important role.

\section{Pathlines}

Figure 7 shows the oil flow path lines obtained on the end wall for $\mathrm{S} / \mathrm{Ch}=0.42,0.7$, 0.84 and 1.04 respectively. The oil flow path lines are colored by particle ID number. It shows common secondary flow features i.e. cross flow, saddle point, separation line and reattachment line. A separation line is developed along the suction side of the blade which is clearly and distinctly visible for higher space-chord ratio values. This suction side separation line drifts away from suction side as space-chord ratio is increased. The locations of the saddle-points are closer to the leading edge for lower $\mathrm{S} / \mathrm{Ch}$ values. 
A common feature observed near the end walls is the occurrence of threedimensional separation of the boundary layer, upstream of' the blade leading edge. As air reaches the leading edge of the turbine blade, a strong vortex (horseshoe vortex) is formed at the junction of the turbine blade and the endwall (Fig. 7). One leg of the horseshoe vortex is convected around the leading edge of the suction surface and remains close to the suction surface endwall corner. This is named as "suction side leg of the horseshoe vortex. The other leg called "pressure side leg of the horseshoe vortex crosses the flow passage from pressure side to the suction side of the adjacent blade due to the prevailing pressure gradient. Due to cross flow in the end wall boundary layer, the horseshoe vortex is pushed towards the suction side of the adjacent blade. Later the vortex lifts off the end wall and the size of the vortex increases and emerges as passage vortex from the blade passage.

Total pressure loss coefficient contours and secondary velocity vectors are shown in Fig. 8. As space-chord ratio is increased, passage vortex migrates towards the mid span caused by the greater blade loading associated with the increased mass flow rate. The wake shows the same structure at different space-chord ratio, but loss cores are detached from endwall as the space-chord is increased. Obviously for different S/Ch values, the start of the vortex and its migration and its impact on the suction side boundary layers will present different characteristic for different $\mathrm{S} / \mathrm{Ch}$ values. The size of the vortex increases with $\mathrm{S} / \mathrm{Ch}$.

The core of the passage vortex occurs at different locations. For the smaller S/Ch, the vortex appears closer to the endwall and suction side of the blade. For larger $\mathrm{S} / \mathrm{Ch}$, the vortex core moves away from the suction side towards the pressure side. The loss contours show that the secondary flow is stronger for larger S/Ch. This is because for the large S/Ch the flow control capacity becomes worse than that of small S/Ch. Owing to the occurrence of the passage vortices, and their interactions for the large S/Ch cases, the secondary flow is very strong. The strong threedimensional effects dominate the whole passage for large S/Ch. However for smaller $\mathrm{S} / \mathrm{Ch}$ the flow phenomenon is different. The vortex is confined to the end wall region.

\section{Pitchwise Mass Averaged Total Pressure Loss Coefficient}

The variation pitchwise mass averaged total pressure loss coefficient with span is shown in Fig.9. The loss is highest on the end wall due to new skewed boundary layer and it becomes minimum slightly away from the endwall. The distance at which the loss becomes minimum seems to be function of $\mathrm{S} / \mathrm{Ch}$. The loss increases again forming a second peak. The second peak is due to the cross channel deflection of the low energy boundary layer fluid from the pressure surface to the suction surface. This low energy fluid gets mixed with the pressure surface leg of the horse shoe vortex and forms into passage vortex. The vortex gets strengthened as it moves towards trailing edge with more and more low energy fluid and emerges from the blade little away from the end wall. The loss remains more or less same from $Z=0.1$. The loss at mid span is indicative of the profile loss and it gradually decreases as the space-chord ratio is increased. However effect of space-chord ratio on profile losses beyond $\mathrm{S} / \mathrm{Ch}=0.7$ appears to be minimum. 
Figure 10 shows variation pitchwise mass averaged secondary loss coefficient with span. Highest peak of secondary losses occurs for the lowest space-chord ratio of 0.42 . As space-chord ratio is increased, cross channel flow increases, secondary loss core moves towards the midspan disturbing main passage flow leading to additional secondary flow losses.

\section{Pitchwise Momentum Averaged Flow Angles}

The angles are momentum averaged and are presented in Figs. 11 and 12. The exit angle is maximum at the end wall due to turning of flow (Fig. 11). It decreases and reaches its lowest value slightly away from the end wall. As S/Ch is increased, the spanwise distance at which flow angle becomes minimum also increases. For $\mathrm{S} / \mathrm{Ch}=1.04$, the value is minimum at $Z=0.1$. Thereafter, the angle slightly increases and then remains constant up to the midspan. Since the guidance to the fluid decreases with increase in space-chord ratio, flow angle becomes less. This is evident from Fig. 11. As space-chord ratio is increased passage vortex migrates towards midspan with increased size; as a consequence the pitchwise angle distribution evidences high secondary deviation for higher space-chord ratio values, (Fig.12).

\section{Pitchwise and Spanwise Averaged Total Pressure Loss Coefficient}

The mass averaged total pressure loss coefficient is shown along the axial distance in Fig. 13. The loss increases slowly up to $x / b=0.2$ where $x$ is axial distance and $b$ is axial chord. The effect of space-chord ratio is not felt up to this axial distance. The total pressure loss coefficient then increases rapidly until the trailing edge. The formation of the passage vortex which is an amalgamation of pressure side leg of the horse-shoe vortex (hence inlet boundary layer) and cross channel end wall boundary layer fluid. The vortex grows in size as it passes through the blade passage. The growth in size as it passes to be function of space-chord ratio. For smallest $\mathrm{S} / \mathrm{Ch}$ ratio of 0.42 , the total pressure losses are highest. This could be due to the fact that the vortex size as percentage of the passage width is large and the obstruction caused by the narrow passage width lead to greater frictional losses. Though the vortex was found to be growing in size and moving away from the end wall and suction surface, the passage width also increases with increase in space-chord ratio. In addition, frictional losses will become less as $\mathrm{S} / \mathrm{Ch}$ is increased. The combined effect is that the total pressure losses are reduced with increase in S/Ch ratio. However, the effect of S/Ch ratio beyond 0.42 is not very significant on losses.

Figure 14 shows mass averaged loss coefficients. Since the boundary layers thickness is constant, the loss due to inlet boundary layer remains more or less constant for all space-chord ratios. The loss at midspan is indicative of the profile loss. Profile loss gradually decreases as the space-chord ratio is increased. However effect of space-chord ratio on profile losses beyond $\mathrm{S} / \mathrm{Ch}=0.7$ appears to be minimum. The increase in secondary loss coefficient with $\mathrm{S} / \mathrm{Ch}$ is milder compared to the change in profile loss coefficient. With the result, total pressure loss coefficient decreases initially with increase in $\mathrm{S} / \mathrm{Ch}$ and then exhibits slight increasing trend. The total pressure loss coefficient has minimum value at $\mathrm{S} / \mathrm{Ch}=0.84$ and can be considered as an optimum value for the present geometry. 


\section{CONCLUSIONS}

As space-chord ratio is increased the secondary loss coefficient increases primarily due to the increased blade loading resulting in increased cross channel deflection. On the other hand, blade frictional losses come down when the space-chord ratio is increased. Hence, there will be on optimum space-chord ratio for a given geometrical and aerodynamic conditions. From the present computational studies $\mathrm{S} / \mathrm{Ch}=0.84$ shows minimum total pressure loss. Secondary loss distribution is mainly influenced by the space-chord ratio. It causes changes in loss contour shape and in the location and magnitude of secondary flows. A smaller S/Ch ratio may cause smaller total pressure losses due to better guidance; on the other hand, small $\mathrm{S} / \mathrm{Ch}$ ratio causes more blockage for the flow thereby increasing frictional losses. In the present investigations, the latter effect seems to be dominating the former effect. There is overall optimal $\mathrm{S} / \mathrm{Ch}$ for which the losses are minimal.

\section{REFERENCES}

[1] Langston, L. S., Nice, M. L. and Hooper, R. M. ,"Three-dimensional flow within a turbine cascade passage", ASME Journal of Engineering for Power, Vol. 99, pp. 21-28, (1977).

[2] Aunapu, N.V., Ralph, J. V., Karen, A. F. and Ryan M. S., "Secondary flow measurements in a turbine passage with endwall flow modification", ASME Journal of Turbomachinery, Vol. 122, pp. 651-658, (2000)

[3] Dossena, V., D'Ippolito, G. and Pesatori, E., "Stagger angle and pitch -chord ratio effects on secondary flows downstream of a turbine cascade at several offdesign conditions". ASME, Proceedings of ASME Turbo Expo2004, 1-9, (2004).

[4] Sharma, O. P. and Butler, T. L., "Predictions of endwall losses and secondary flows in axial flow turbine cascades", ASME, 86-GT-228, (1986).

[5] Wang, H.P., Olson, S.J., Goldstein, R.J. and Eckert, E.R.G., "Flow visualization in a linear turbine cascade of high performance turbine blades", ASME Journal of Turbomachinery, Vol. 119, pp. 1-9, (1997).

[6] Moore, J. and Adhye, R. Y., "Secondary flow and losses downstream of a turbine cascade", ASME Journal of Gas Turbines and Power, Vol. 107, pp. 961968, (1985).

[7] Krishna Nanda Kumar and Govardhan, M., "Secondary loss reduction in a turbine cascade with a linearly varied height streamwise endwall fence" International Journal of Rotating Machinery, Vol. 2011, doi:10.1155/2011/352819, pp. 1-16, (2011).

[8] Perdichizzi, A. and Dossena, V., "Incidence angle and pitch-chord effects on secondary flows downstream of a turbine cascade". ASME Journal of Turbomachinery, Vol. 115, pp. 383-391, (1993). 
[9] Xu, C. and Amano, R. S., "Computational analysis of pitch-width effects on the secondary flows of turbine blades", Computational Mechanics, Vol. 34, pp. 111120, (2004).

[10] Govardhan, M., and Pramod Kumar Maharia, "Secondary loss reduction by streamwise fences in a reaction turbine cascade", $7^{\text {th }}$ Jordanian International Mechanical Engineering Conference (JIMEC'7), Amman-Jordan, pp. 27-29, (2010).

Table 1. Details of the cascade.

\begin{tabular}{|l|l|}
\hline Blade chord, ch & $0.102 \mathrm{~m}$ \\
\hline Blade axial chord, a & $0.088 \mathrm{~m}$ \\
\hline Blade inlet angle, $\alpha_{1 \mathrm{~b}}$ & $22^{0}$ \\
\hline Blade exit angle, $\alpha_{2 \mathrm{~b}}$ & $-60^{0}$ \\
\hline Blade height, $\mathrm{h}$ & $0.4 \mathrm{~m}$ \\
\hline Stagger angle, $\gamma$ & $-30^{0}$ \\
\hline Aspect ratio, AR & 3.9 \\
\hline Maximum thickness, $\mathrm{t}_{\mathrm{max}} / \mathrm{ch}$ & 0.298 \\
\hline Trailing edge thickness, $\mathrm{t}_{\mathrm{TE}} / \mathrm{ch}$ & 0.09 \\
\hline Leading edge radius & 0.0143 \\
\hline Incidence angle & $0^{0}$ \\
\hline
\end{tabular}

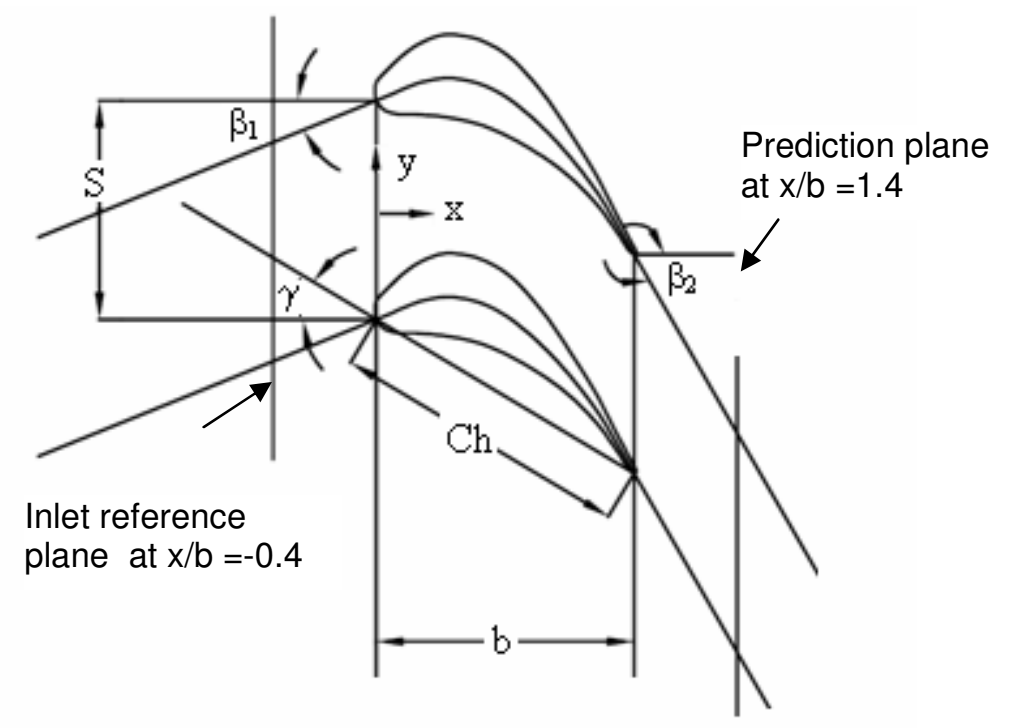

Fig. 1. Two dimensional view of cascade showing different angles and lengths. 

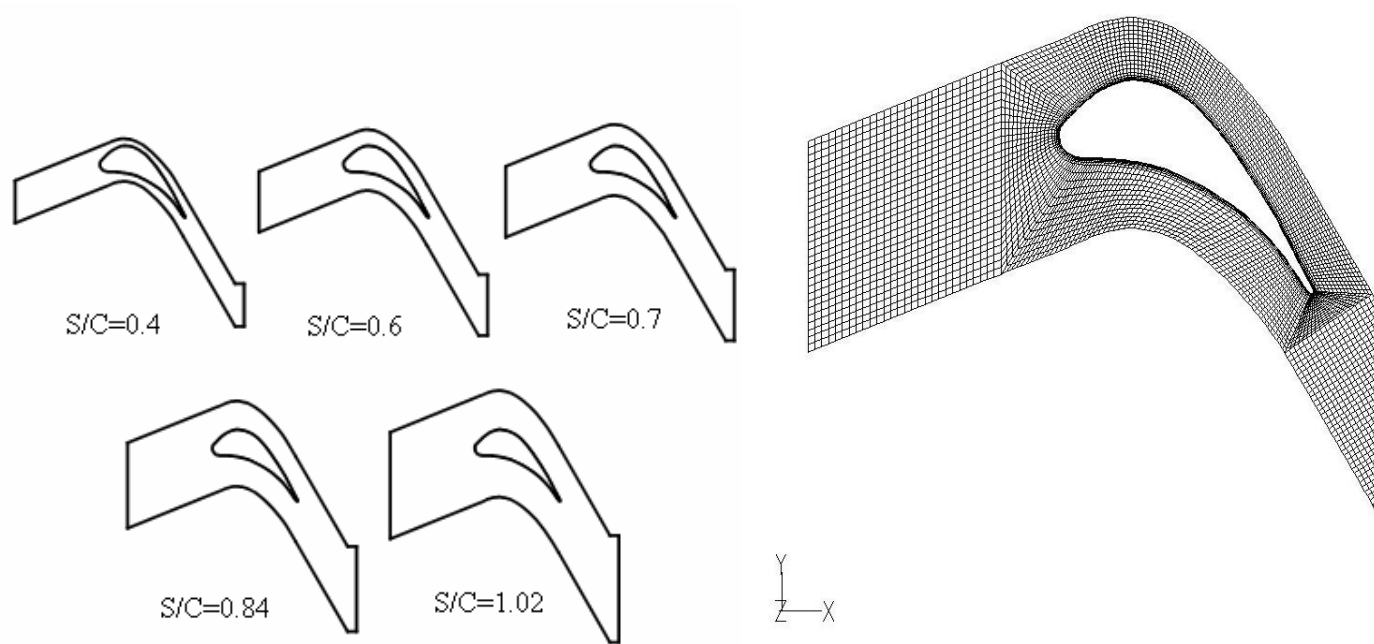

Fig. 2. Different models of space-chord ratio.

Fig. 3. O- type structured meshing.

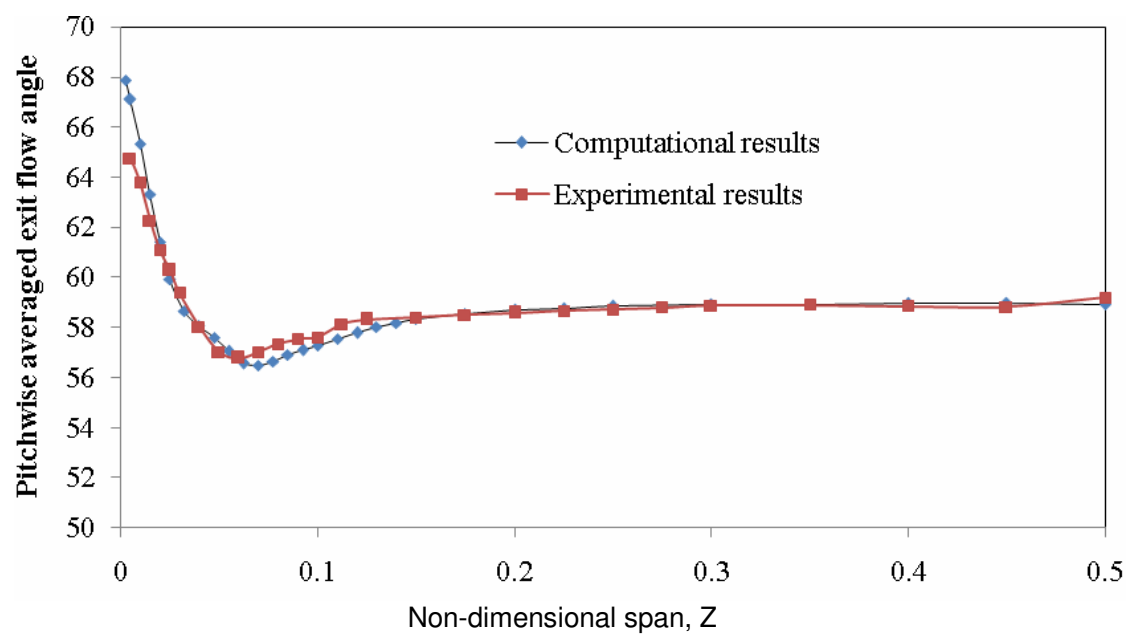

Fig. 4. Variation pitchwise averaged exit flow angle with span, Experimental vs. Computational, $\mathrm{S} / \mathrm{Ch}=0.7$. 


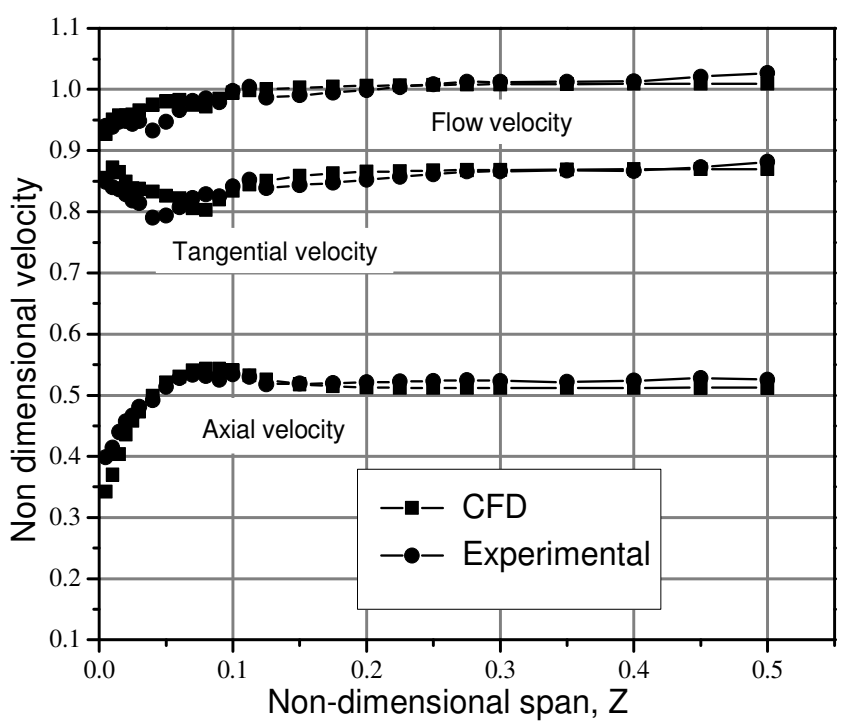

Fig. 5. Spanwise variation of pitch wise mass averaged non-dimensional velocity ratios.

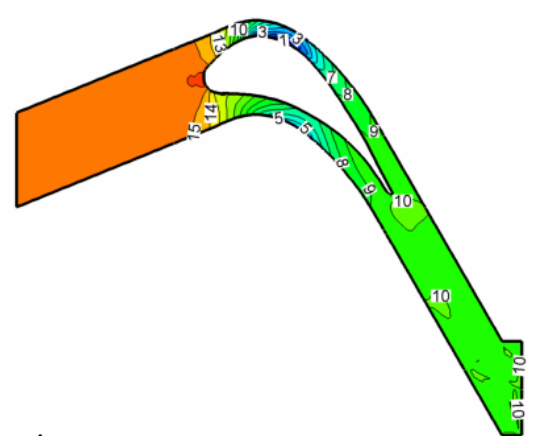

$\mathrm{S} / \mathrm{Ch}=0.42$

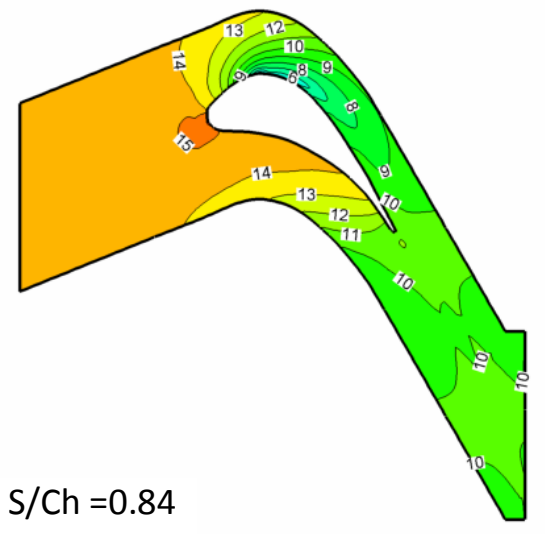

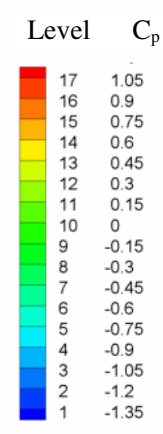

$\mathrm{S} / \mathrm{Ch}=0.70$

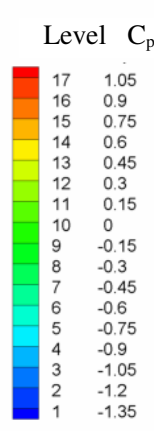

$\mathrm{S} / \mathrm{Ch}=1.04$

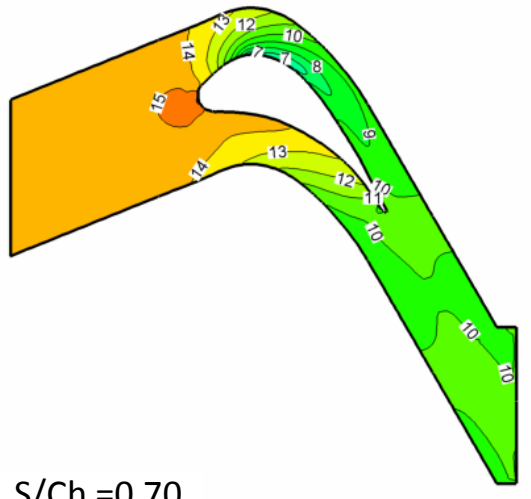

Level $C_{p}$
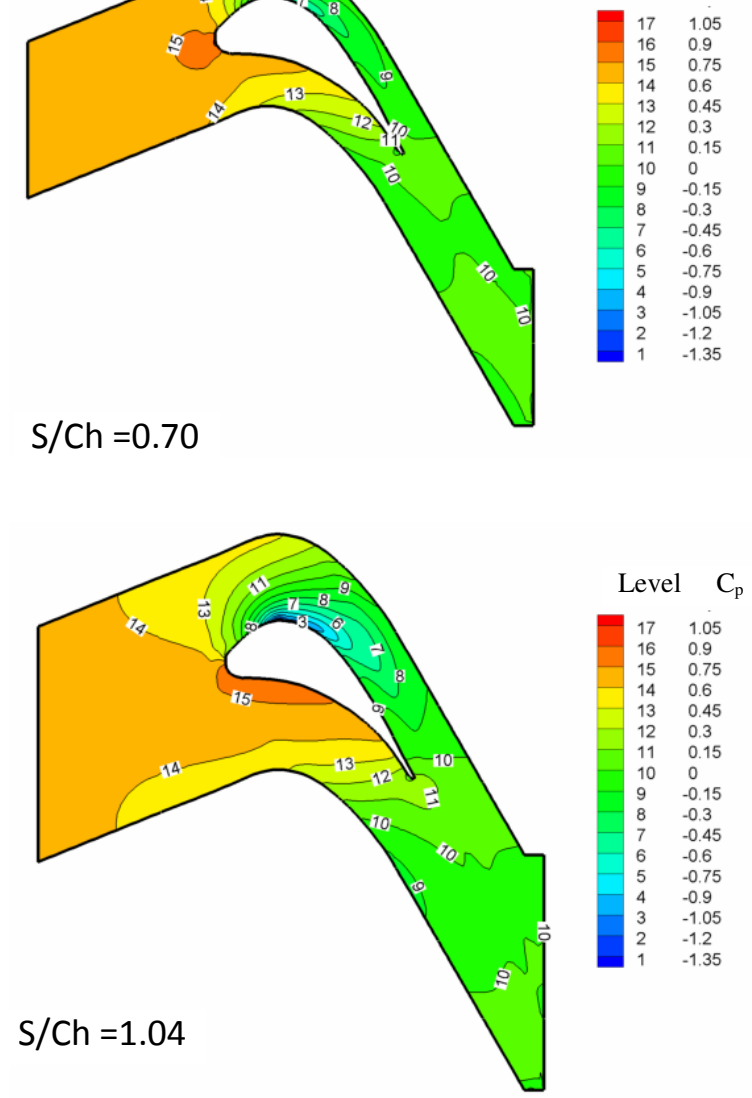

Fig. 6. Surface static pressure coefficient, $C_{p}$ on the endwall. 

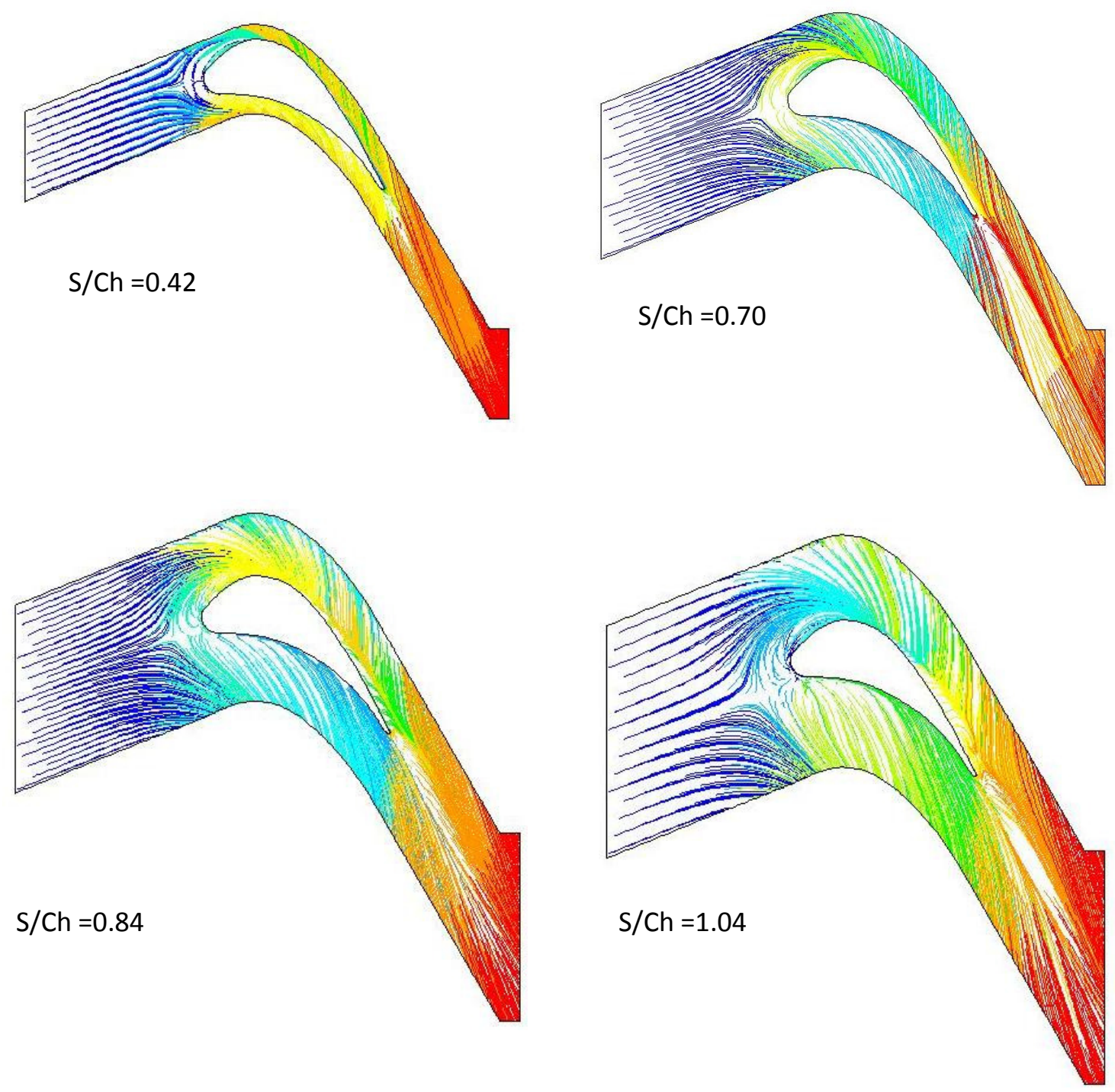

Fig. 7. Path lines colored by particle ID on the endwall. 

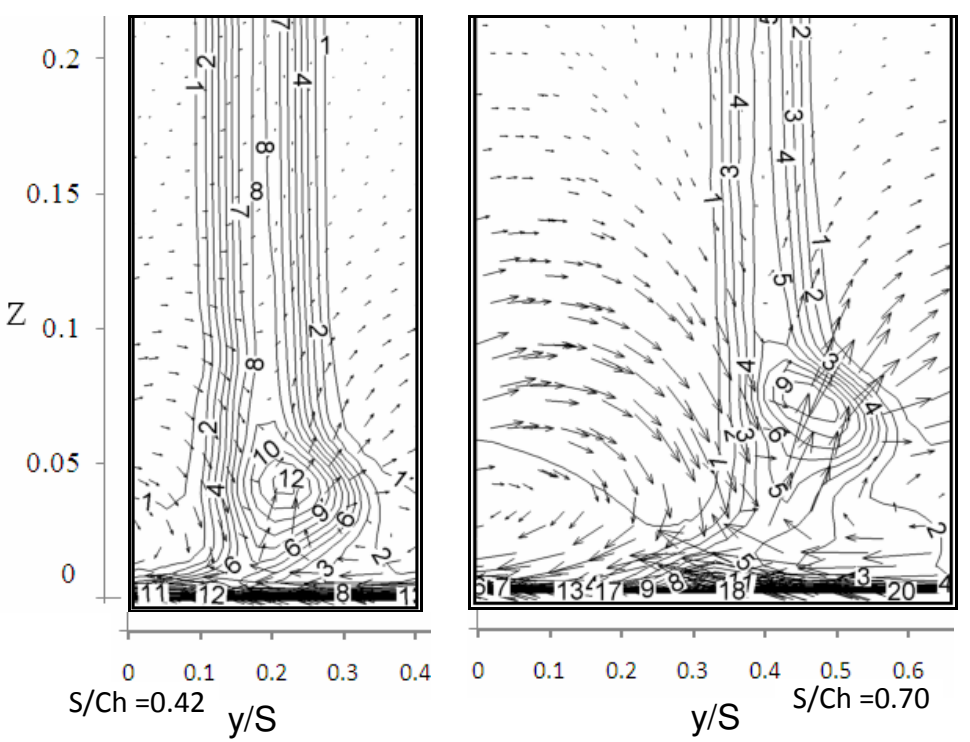

\begin{tabular}{|cl|}
\hline evel & $\Psi_{\text {loss }}$ \\
20 & 1 \\
19 & 0.95 \\
18 & 0.9 \\
17 & 0.85 \\
16 & 0.8 \\
15 & 0.75 \\
14 & 0.7 \\
13 & 0.65 \\
12 & 0.6 \\
11 & 0.55 \\
10 & 0.5 \\
9 & 0.45 \\
8 & 0.4 \\
7 & 0.35 \\
6 & 0.3 \\
5 & 0.25 \\
4 & 0.2 \\
3 & 0.15 \\
2 & 0.1 \\
1 & 0.05 \\
\hline
\end{tabular}
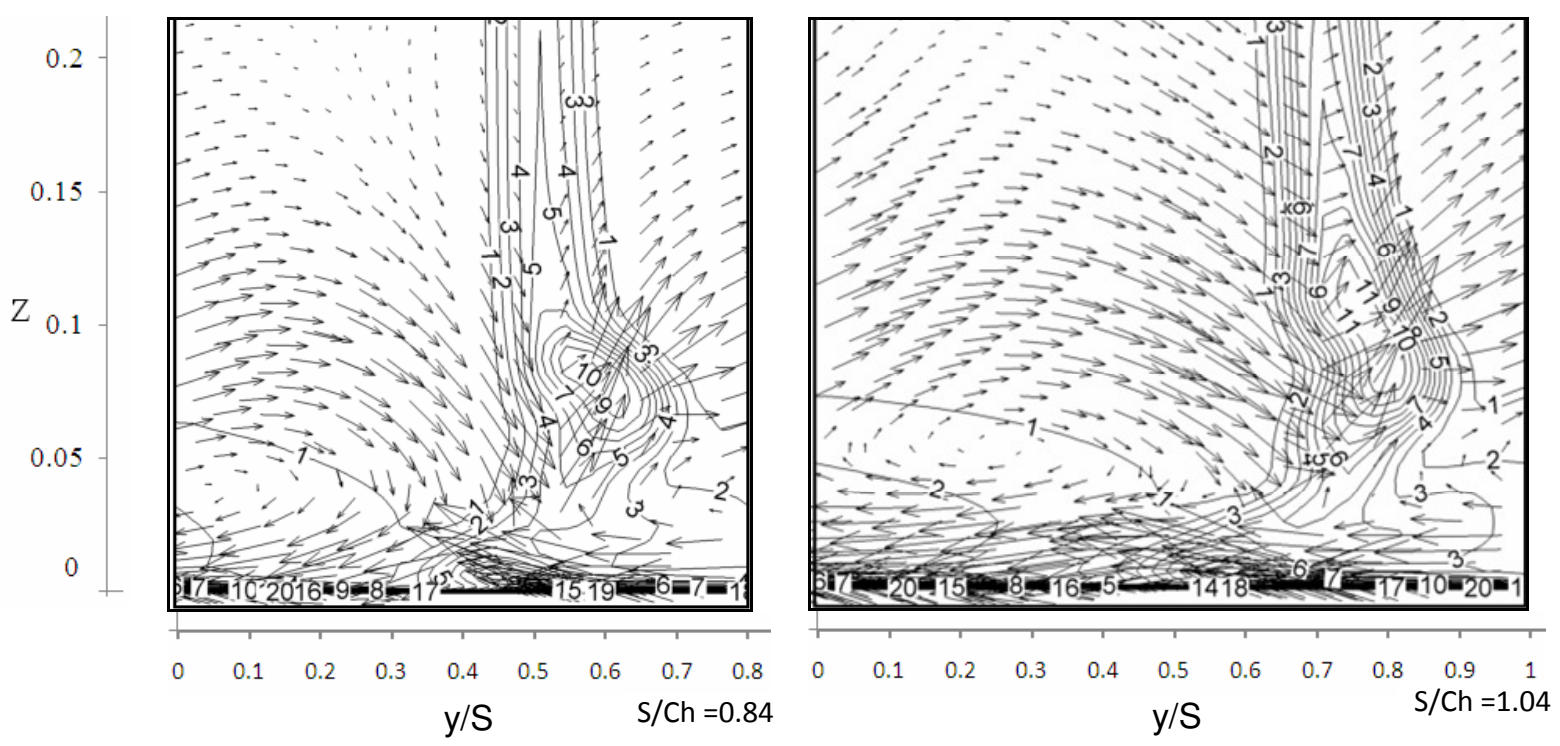

Fig. 8. Influence of space-chord ratio on loss contours and secondary velocity vectors.

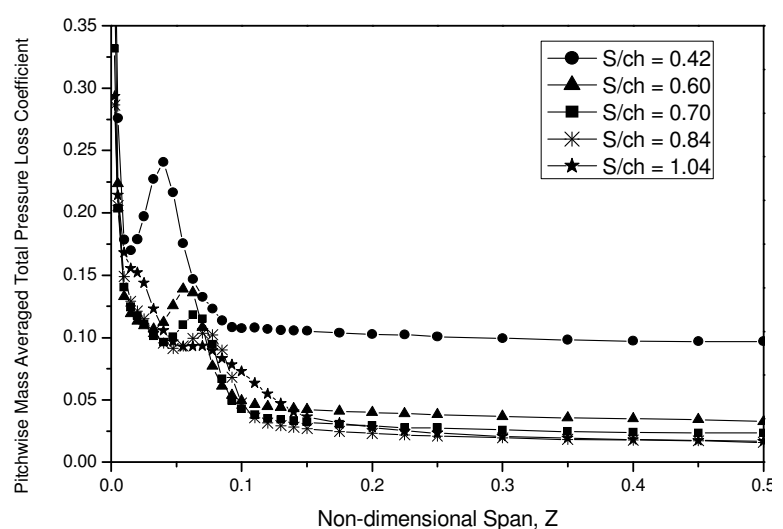

Fig. 9. Variation pitchwise mass averaged total pressure loss coefficient with span

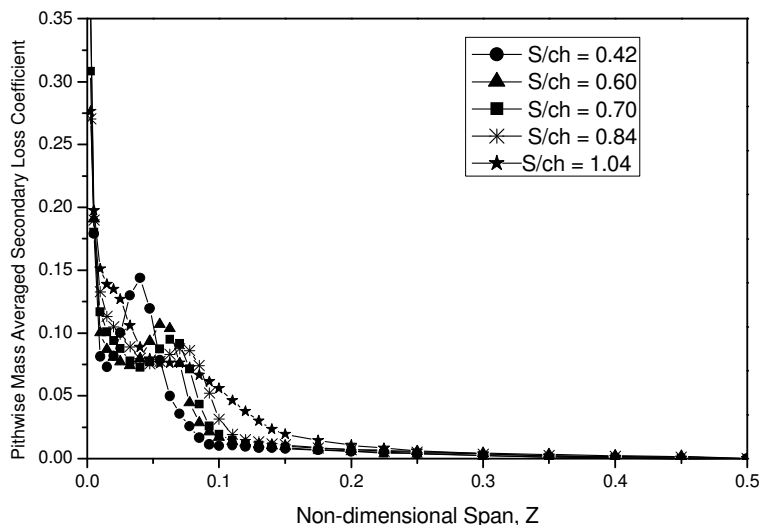

Fig.10. Variation pitchwise mass averaged secondary loss coefficient with span. 


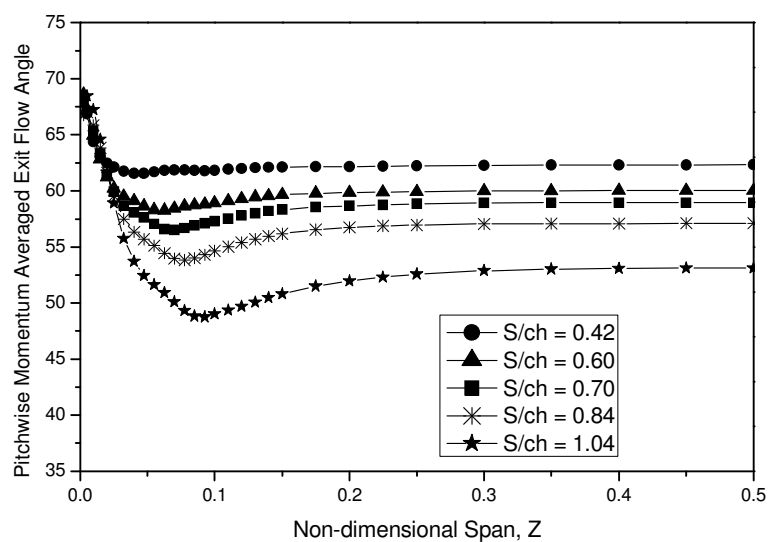

Fig. 11. Variation of pitchwise momentum averaged exit flow angle with span.

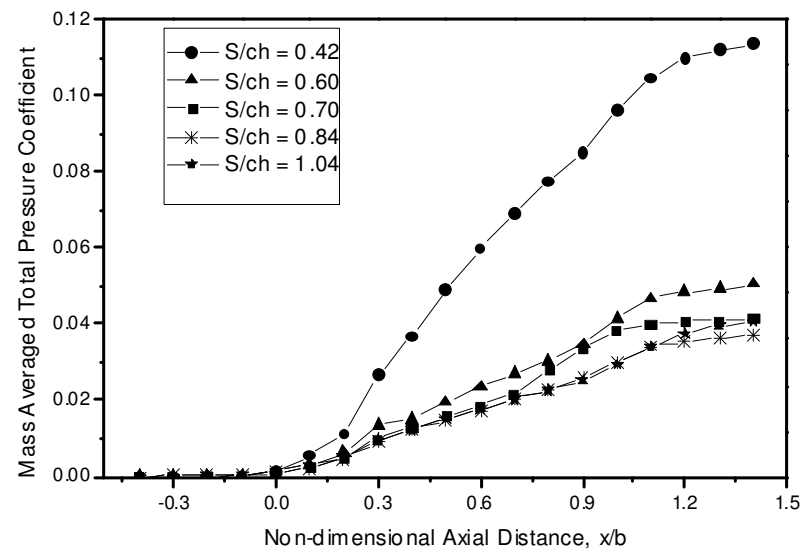

Fig. 13. Axial variations of mass averaged total pressure loss Coefficient

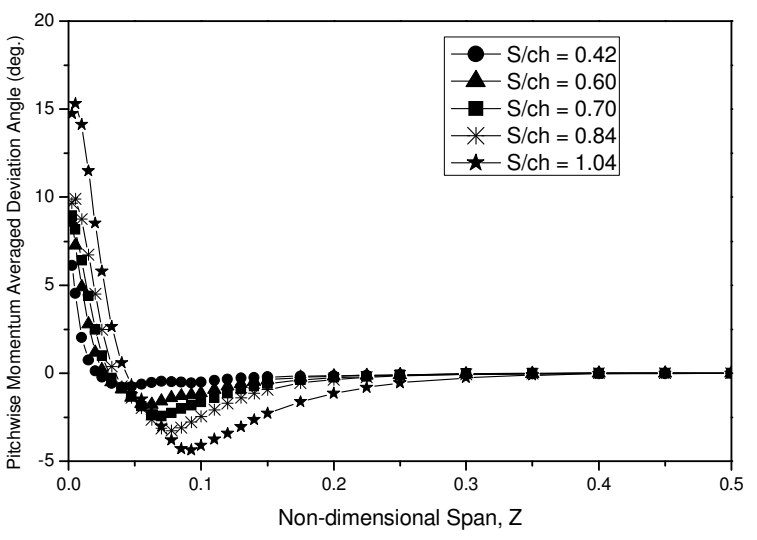

Fig. 12. Variation of pitchwise momentum averaged secondary deviation angle with span.

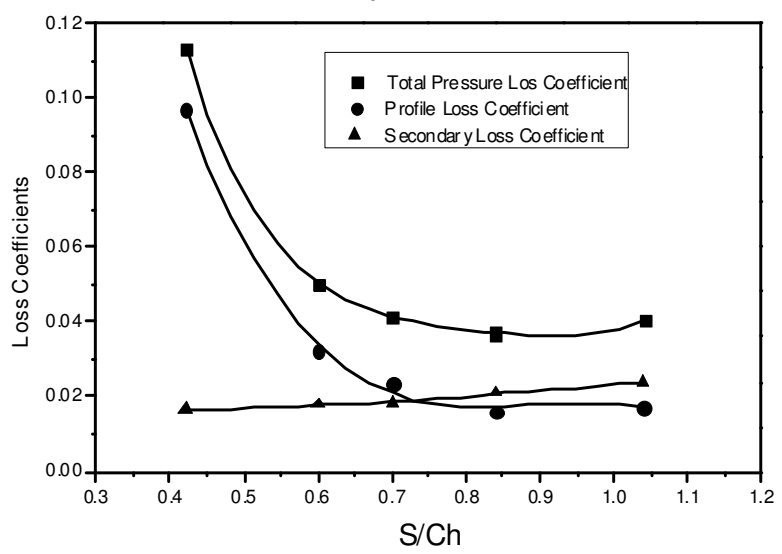

Fig. 14. Variation of mass averaged loss coefficients with space-chord ratio 